$\underline{\text { Review Article }}$

\title{
A REVIEW ON CO-PROCESSED EXCIPIENTS: CURRENT AND FUTURE TREND OF EXCIPIENT TECHNOLOGY
}

\author{
LIEW KAI BIN ${ }^{a *}$, ANAND GAURAVa, UTTAM KUMAR MANDAL ${ }^{c}$
}

aFaculty of Pharmaceutical Sciences, UCSI University. No 1, Jalan Menara Gading, UCSI Height, 56000 Cheras, Kuala Lumpur, bFaculty of Pharmacy, Cyberjaya University College of Medical Sciences. Persiaran Bestari, 63000 Cyberjaya, Selangor, cDepartment of Pharmaceutical Sciences and Technology, Maharaja Ranjit Singh Punjab Technical University (MRSPTU), Bathinda, Punjab 151001, India Email: liewkaia@yahoo.com

Received: 21 Aug 2018 Revised and Accepted: 23 Nov 2018

\begin{abstract}
There is no single-component excipient fulfills all the requisite performance to allow an active pharmaceutical ingredient to be formulated into a specific dosage form. Co-processed excipient has received much more attention in the formulation development of various dosage forms, specially for tablet preparation by direct compression method. The objective of this review is to discuss the emergence of co-processed excipients as a current and future trend of excipient technology in pharmaceutical manufacturing. Co-processing is a novel concept of combining two or more excipients that possess specific advantages that cannot be achieved using a physical admixture of the same combination of excipients. This review article discusses the advantages of co-processing, the need of co-processed excipient, general steps in developing co-processed excipient, limitation of co-processed excipient, technologies used in developing co-processing excipients, co-processed excipients in the literature, marketed products and future trends. With advantages offered by the upcoming newer combination of excipients and newer methods of co-processing, co-processed excipients are for sure going to gain attraction both from academia and pharmaceutical industry. Furthermore, it opens the opportunity for development and use of single multifunctional excipient rather than multiple excipients in the formulation.
\end{abstract}

Keywords: Orally disintegrating tablet, Oral drug delivery, Co-processed excipient, Direct compression

(c) 2019 The Authors. Published by Innovare Academic Sciences Pvt Ltd. This is an open-access article under the CC BY license (http://creativecommons.org/licenses/by/4.0/) DOI: http://dx.doi.org/10.22159/ijpps.2019v11i1.29265

\section{INTRODUCTION}

In the past $10 \mathrm{y}$, the focus of both academia and pharmaceutical industry has been shifted from developing new active pharmaceutical ingredient (API) to formulation technology [1]. Pharmaceutical excipients have played a major role in that shift. Pharmaceutical excipients are defined as the substances other than the API which has been appropriately evaluated for safety and are intentionally included in a drug delivery system [2]. The International Pharmaceutical Excipients Council (2009) defines excipients as the substances which present in a finished pharmaceutical dosage form other than the active drug substance [3]. Excipient can be classified into four categories generally: single entity excipient, a physical blend of multiple excipients, new chemical entity excipient and co-processed excipient [4].

It is generally agreed by the formulation scientist that there is no single-component excipient fulfills all the requisite performance to allow an active pharmaceutical ingredient to be formulated into a specific dosage form [5]. On the other hand, developing a new chemical entity excipient requires a huge sum of investment [6]. To counter this issue, formulation scientist has introduced a novel concept of co-processing which is combining of two or more excipients that possess significant advantages that cannot be achieved using a physical admixture of the same combination of excipients [7]. A co-processed excipient is a combination of two or more compendial or non-compendial excipients designed to modify their physical properties in a manner not achievable by simple physical mixing, and without significant chemical change [2]. By formulating few excipients into a single composite material with specialized manufacturing method leads to an improvement in functionality of the end product [8]. This has become a newer trend in formulation development [9].

Co-processed excipient has received much more attention in the formulation development of various dosage forms such as a tablet, capsule, powder, cream, ointment, and others [10]. It is different from the physical mixture. Physical mixture is just a simple admixture combining few excipients by short duration shear processing. However, in the case of co-processed excipients, they possess performance advantages that cannot be achieved using a physical admixture of the same combination of excipients [11]. Combination of economical excipient with others of optimal quantity of a functional material will produce an integrated product with superior functionality than the simple mixture of components [12]. Co-processing generally does not involve chemical change. The changes in functionality are often contributed by the change in physical properties of the excipient particles [13].

Oral delivery remains the most popular route of drug delivery [14]. It is because the oral drug delivery system has the key advantage of convenient drug administration. Tablets and hard gelatin capsules constitute a major portion of drug delivery systems that are currently available due to its convenience of self-administration, compactness and simple manufacturing process $[15,16]$. Moreover, the drug is found to be more stable in solid dosage form than liquid dosage form [17].

The most common methods to manufacture tablets are wet granulation, dry granulation and direct compression [18]. If the major components of a formulation have already possessed good fluidity and compressibility, granulation would be redundant. Direct compression was reported as one of the most preferred methods due to some advantages such as time-saving, ease of production due to few steps involved, the absence of heat and moisture in the process [19]. In the survey by Shangraw and Damarest (1993), it was shown that direct compression was the most preferred tablet manufacturing method compared to wet granulation and roller compaction. About $41 \%$ of the companies indicated that direct compression was the method of choice, and $41.1 \%$ indicated that they used both direct compression and wet granulation. Only $1.7 \%$ of the respondents indicated that they never used direct compression and $15.5 \%$ indicated that the process was not recommended [19].

A further advantage of direct compression is that tablets disintegrate into the primary particles bypassing granular aggregation stage. As a result, the effective surface area increases and dissolution of the drug 
become faster [20]. However, the method encounters drawbacks due to lack of suitable excipients for direct compression application. Two major factors of powder characteristic which will critically affect the process of direct compression are compressibility and flowability [21, 22]. The majority of the excipients that are currently available fail to meet the desired set of functionalities. It creates urgency for the development of high functionality excipients [23]. Therefore, the coprocessed excipient can play a role here to fill the gap of technology in direct compression.

The aim of this article was to perform a literature review on coprocessed excipient and compile as well as discussing the coprocessed excipients available in the market and in literature. A detail literature review was conducted by searching keywords such as: a co-processed excipient, orally disintegrating tablet, oral drug delivery, tablet, direct compression, formulation, solid dosage form and powder. The search was done in the search engines including Science Direct, Science and Technology of Advanced Materials, PLOS ONE, Directory of Open Access Journals, CiteSeer and Google Scholar.

\section{Advantages of co-processing}

\section{Improved compressibility}

Compressibility is an important factor of consideration in tablet development. Ideally, a compacted tablet is formed once the compression force is removed (6). However, all the conventional tablet excipients lack this plastic property. Majority of the co-processed adjuvants overcome this limitation. Flores et al. (2000) reported that the compressibility of Ludipress ${ }^{\circledR}$, a co-processed adjuvant, is superior than the physical mixtures of their constituent excipients $[24,25]$.

\section{Better dilution potential}

Dilution potential is defined as the ability of the excipient to retain its compressibility even when diluted with another low compressibility material. API and many inactive excipients have poor compressibility. On the other hand, a co-processed excipient with high dilution potential is desirous so that the compressibility properties of the mixture of powder blend can be maintained even when diluted with other excipients [26]. Cellactose ${ }^{\circledR}$ is shown to have a higher dilution potential than the physical mixture of its constituent excipients [27].

\section{Reduced lubricant sensitivity}

Generally, hydrophobic lubricant provides a negative impact on the compression behavior of powder blend. Plasticity contributes brittle characteristic to an excipient. The presence of a large degree of brittle character in a co-processed excipient provides low lubricant sensitivity because it prevents the formation of a coherent lubricant network by forming newly exposed surfaces upon compression, thus breaking up the lubricant network [6].

\section{Ease of production}

Co-processed excipient simplifies the tablet formulation and development steps. Tablet formulation normally consists of weighing of active ingredient and various excipients followed by mixing, granulation, drying, sieving, and compression. Weighing of each ingredient might be time-consuming, and it may incur error in the process. Use of co-processed excipient might simplify the production process and reduces the rate of error [28].

\section{Improved flow properties}

The co-processed excipient is reported to have better flow properties compared to its individual constituent or physical mixture by controlling the particle size distribution [29]. Good flowability is desired especially in case of high-speed rotary tablet machine [6]. The co-processing excipients play an important role in improving flow property of the powder mass ready for compression. A study showed that the co-processed Cellactose ${ }^{\circledR}$ has better flow than cellulose and lactose due to the spray drying technique used which resulted in particles of spherical shape and even surfaces [30].

\section{Fast disintegration}

Fast disintegration is compendial and formulation requirement for immediate release and orally disintegrating dosage form [31]. Co- processed adjuvants, by virtue of their high solubility, swelling and wicking property, provide rapid disintegration to the developed formulation.

\section{Stability}

The co-processed excipient should be stable physically and chemically [6]. The ingredients used should be inert and not interact with the API.

\section{Cost saving}

The manufacturer uses a single excipient with multiple functional properties, thereby reducing the number of excipients used and labor cost involved in their processing other than direct compression method. Use of co-processed adjuvants simplifies manufacturing process which leads to time and cost saving.

\section{Need of co-processed excipients}

A list of available co-processed excipients is provided in table 1. However they are not sufficient considering the diverse need of the pharmaceutical industries, specially for preparation of ODT tablets. There are only a few excipients are suitable for direct compression application. Most of the excipients having drawbacks such as lack of compressibility, poor flowability, lack of cohesion properties or lubrication [32]. As a result, a blend of few ingredients is required to achieve satisfactory condition prior to direct compression [33]. Moreover, the advance in tableting machinery has resulted in high-speed tablet machine with short duel times. Operation of this machine requires excipients with good compressibility flow property [4].

The role of co-processing comes into the picture by interacting two or more excipients at the sub-particle level, aimed at providing a synergy of functionality improvements, as well as masking the undesirable properties of the individual excipients [2]. The advancement and maturation of co-processing technology explore the possibility to produce tailor-made "designer excipients" to cater to various specific needs required for formulation development [32].

\section{General steps in developing co-processed excipients}

In order to design a new co-processed excipient which meets the functionality requirement of a specific application, few steps are important to take into consideration.

\section{a. Identification of the group of excipients to be co-processed}

A good co-processed excipient should look into the balance between plasticity and brittleness of a material [34]. Combination of plastic and brittle material nullifies storage of undesirable elastic energy during the compression. This will produce a product with a small amount of stress relaxation and a reduced tendency of capping and lamination thereby optimum tableting performance [35]. The combination of excipient chosen should complement each other and provide synergistic effect to achieve the desirable characteristics [6].

\section{b. Assessing the particle size}

Particle size will affect the compressibility and flowability of the end product. If the participating excipients have variation in initial particle sizes, the focus should be given to produce the final coprocessed adjuvant with uniform particle size.

\section{c. Selecting a suitable technique to co-process various excipient}

There are many methods which can be used for co-processing such as wet granulation, melt granulation, freeze drying, spray drying, hot melt extrusion [36-39]. A comprehensive detail has been provided later in this review.

\section{d. Optimizing the process and the proportion of each excipient}

This can contribute to functionality variations in the end product. Various optimization techniques and experimental designs with sound statistical analysis can be employed to obtain a final product with desired functionalities.

\section{Limitation of co-processed excipient}

Although co-processed excipient shows a list of promising benefits, however, there are few drawbacks in using of co-processed 
adjuvants. Co-processed adjuvant is available as pre-mixed at a fixed ratio of an individual constituent. The user has no freedom to alternate the ratio of the excipient [40]. Moreover, co-processed adjuvant lacks the official acceptance in pharmacopeia [41]. For this reason, a co-processed adjuvant is not accepted by the pharmaceutical industry unless it exhibits significant advantages in the tablet compaction when compared to the physical mixtures of the excipients [2].

\section{Technologies used in the manufacturing of co-processed excipients roller compaction}

Roller compaction uses the principle of dry granulation for particle bonding. This method is useful for ingredients which are sensitive to moisture and heat. The powder blend is mixed uniformly and compressed between counter-rotating rollers to form a ribbon of compacted material that is then milled into granules of appropriate particle size [42-44].

\section{Wet granulation}

Wet granulation is a conventional and simple method for coprocessed adjuvant production. Fluid bed granulators and highshear mixers are two commonly used equipment used for the same. In fluid bed granulation, the powder mix is subjected to fluidization by a flow of air injected upwards through the bottom screen of the granulator. The binding solution is sprayed in the opposite direction to the air flow on the powder bed. The solid particles are mixed with the liquid droplets and hit the bed which results in adhesion and eventually the formation of granules. Partial drying by the fluidizing air occurs continuously during granulation [45-47].

In high-shear granulation, an impeller maintains the powder in agitation in a closed vessel. The binder solution is sprayed from the top. Development of large agglomerates is prevented by high shear force. With the new single-pot technology, drying occurs in the same system. The granules formed are understandably denser than those obtained in fluid bed granulation [48].

\section{Hot melt extrusion}

Hot melt extrusion uses heat with a temperature greater than $80^{\circ} \mathrm{C}$. This method is not suitable for thermo labile materials. The excipients are melted and then pressurized through the die and solidify into a variety of shapes. The solvent is not required in the process as the molten polymer can function as a thermal binder [49].

\section{Spray drying}

Spray drying generally involves five steps: Concentration of feedstock, atomization, droplet-air contact, droplet drying and separation and collection [50-51]. The technique transforms a feed which might be a solution, suspension or dispersion into dried particulate form by spraying it into a hot drying medium. The particle-particle bonding of excipients occurs during the process. The increased droplet surface area and high temperature cause the formation of spherical shape particles with improved flowability and suitable direct compression application such as Starlac ${ }^{\circledR}$.

\section{Roller drying}

A roller dryer is used to dry the homogeneous solution or dispersion containing the pre-blended excipients. Meggelaars et al. (1996) applied this technique to co-process lactose with sorbitol and lactitol [52]. The temperature used was sufficiently high to obtain an end product that consists principally of $\beta$-lactose in crystalline form.

\section{Co-transformation}

Co-transformation technique involves the application of heat or solvent effect to "open-up" (swelling) the particle of one excipient. The other excipients are incorporated into the "opened-up" structure of the aforementioned excipient. The augmented excipient strengthens the functionality of the end product $[53,54]$.

\section{Milling}

A roller mill, ball bill, bead mill, millstone mill, jet mill or a hammer mill can be used to perform milling or dry grinding. The excipients are premixed and passed through a high-speed milling machine. During the process of milling, the particles come in contact with each other and form bonds when they are subjected to force to mill or pass through the screen. Rao et al. (2012) applied this technique to coprocess cross-linked polyvinylpyrrolidone and calcium silicate [55].

\section{Melt granulation}

The blend of excipients are mixed with a meltable binder (normally at solid state below $80^{\circ} \mathrm{C}$ ). The mixture is subjected to heat above the melting point of the binder with continuous blending in order to break the mass into agglomerates. The cooled agglomerates are finally screened to obtain granules with desired size [56-57].

\section{Solvent evaporation}

Solvent evaporation takes place in a liquid manufacturing vehicle. The coating excipient is dissolved in a volatile solvent which is immiscible with the liquid manufacturing vehicle, followed by dissolving or dispersing the core excipient in the coating solution. Agitation force is applied to achieve the desired encapsulation size. Heat is used to evaporate the solvent [4].

\section{Co-processed excipient in the literature}

\section{Microcrystalline cellulose (MCC) and calcium carbonate}

Mehra et al. (1986) patented a co-processed excipient of microcrystalline cellulose and calcium carbonate. The co-processed excipient was used to produce a directly compressed vitamin tablet. The invention was economical and exhibited low lubricant sensitivity [58].

\section{Lactose, polyvinylpyrrolidone (PVP) and crospovidone}

Lang (1991) reported a blend of lactose, PVP and crospovidone which was produced through spray drying, spray granulation or wet granulation method. The novel direct tableting auxiliaries exhibited good flow, good compressibility under low pressure, excellent disintegration properties coupled with great hardness and low abrasion [59].

\section{$\beta$-lactose and sorbitol}

Meggelaars et al. (1996) prepared a homogeneous mass consisting of a dried solution of high $\beta$-lactose content with sorbitol ranges from $1-15 \% \% \mathrm{w} / \mathrm{w}$. Roller drying technique was used in the drying process. The excipient can be used to prepare tablet with exclusive hardness [52].

\section{Cornstarch and polyvinylpyrrolidone}

Menon et al. (1996) described a co-processed excipient consisting of cornstarch and polyvinylpyrrolidone produced using fluid bed spray granulation method. The invention is free-flowing and exhibits good compressibility [60].

\section{Colloidal silicon dioxide and MCC}

Sherwood et al. (1996) patented a novel MCC-colloidal silicon dioxide excipient that was found to be free flowing, possess excellent disintegration properties and have improved compressibility relative to normal "off the shelf" commercially available MCC [61].

\section{Guar gum and MCC}

Ratnaraj and Reilly (1997) produced a co-processed excipient for the chewable tablet by thoroughly mixing an aqueous dispersion of MCC and guar gum under high shear conditions at room temperature. The homogenous dispersion was then spray dried to an aggregate powder having substantially spheroidal-shaped particles. The excipient has improved compressibility and mouth feel. It reduces tooth packing [62].

\section{Directly compressible sucrose}

The invention contains $95 \%$ sucrose and $5 \%$ of maltodextrin. This sugar-based excipient is free-flowing, compressible and has a pleasant taste and mouthfeel which can be helpful in masking the bitter taste of API [63]. 


\section{MCC and methylcellulose}

Augello and Vladyka (1999) invented a co-processed excipient by wet granulating MCC and methylcellulose. The compositions were then subjected to spheronizing into spheres having a smooth uniform surface. The end product serves as a coating polymer which provides complete taste masking of a bitter drug such as ibuprofen while having no adverse impact on the bioavailability of the drug [64].

\section{MCC and sodium alginate}

The invention is a wet granulation binder type excipient by Augello and Reier (1999). A uniform aqueous slurry of MCC and sodium alginate was formed firstly, followed by drying the slurry to granular particular [65].

\section{Alfalfa, MCC and calcium carbonate}

Ibrahim and Saraiya (2001) developed a co-processed excipient comprised of alfalfa root, MCC and calcium carbonate. Spray dried procedure was used in the development process. The said product was applied to formulate vitamin and nutritional supplements [66].

\section{MCC and maltodextrin}

Buliga et al. (2002) blended MCC and maltodextrin and sprayed dried the dispersion. The invention was reported to mix with carboxymethyl cellulose to produce a dry blend that can be used in food and cosmetic application as stabilizer [67].

\section{Rice starch and MCC}

Limwong et al. (2004) invented a co-processed excipient comprising of rice starch and MCC. Composite particles of rice starch and MCC were fabricated by spray-drying technique to be used as a directly compressible excipient. The compressibility was greater than commercial spray-dried rice starch (Eratab), coprocessed lactose and microcrystalline cellulose (Cellactose), and agglomerated lactose (Tablettose), but, lower than microcrystalline cellulose (Vivapur 101) [36].

\section{Calcium phosphate and fatty acid wax}

Cucula et al. (2006) produced a co-processed excipient containing calcium phosphate and fatty acid wax (glyceryl behenate or glyceryl palmitostearate) using melt granulation method. Co-processing of calcium phosphate with fatty acid wax overcomes the abrasiveness and capping issues normally associated with calcium phosphate. It was applied to formulate venlafaxine HCL modified release tablet, and venlafaxine besylate extended-release tablet [68].

\section{Sorbitol and mannitol}

Norman et al. (2006) reported a blend of sorbitol and mannitol prepared by dissolving mannitol powder and sorbitol powder into a solution. The solution was then dried in an air stream and forming a composition that completely dissolves in the oral cavity within 60 seconds. The invention is suitable for orally disintegrating tablet application [69].

\section{Crospovidone and sodium starch glycolate}

Gohel et al. (2007) developed the co-processed excipient through wet granulation and tray drying technique. Blend of crospovidone and sodium starch glycolate was added to isopropyl alcohol for wet granulation. The wet mass was sieved and dried in a tray dryer. The end product exhibited good flow property, compaction and disintegration property. The invention was applied as a superdisintegrant in the formulation of cefiximetri hydrate and ibuprofen tablet [37].

\section{Copolymer of vinylpyrrolidone (VP) and vinyl acetate (VA) and MCC}

Halder et al. (2007) developed a co-processed adjuvant containing a copolymer of vinylpyrrolidone, vinyl acetate and MCC. This synergistic binder composition was applied to produce tablets with exclusive hardness and acceptable friability. It is suitable to be used in tablet formulation containing poorly compressible drug [70].

\section{MCC and mannitol}

Slurry of MCC and mannitol were sprayed dried to spherical particulate. The composition had an improved compatibility profile, lubricant sensitivity, and ejection profile compared to the physical mixture and individual component [71].

\section{Mannitol and calcium silicate}

A co-processed excipient which is suitable for orally disintegrating tablet application was developed by Gandhi et al. (2009). Mannitol was dispersed in water followed by dispersing calcium silicate in the solution. The mixture was spray dried to granules. The tablet produced by compression of the excipient disintegrated in less than 60 seconds [72].

\section{Crospovidone and croscarmellose sodium}

Nagendrakumar et al. (2009) blended croscarmellose sodium and crospovidone in ethanol. The mixture was stirred until most of the ethanol evaporated. The wet coherent mass was sieved and dried in a hot air oven. The invention serves as a co-processed superdisintegrant. It was applied to formulate granisetron fast dissolving tablet [73].

\section{Mannitol and cellulose}

Patel SS and Patel NM (2007) prepared a co-processed excipient of mannitol and cellulose for dispersible tablet application. The end product was prepared using the freeze-thawing method and was claimed to have an improvement in flowability, compatibility and dissolution rate of a model drug [9].

\section{Povidone and glyceryl behenate}

Ayyappan et al. (2010) developed a co-processed adjuvant comprising povidone and glyceryl behenate which was claimed to function as binder and lubricant with good flow and compressibility. The co-processed excipient was applied to manufacture tramadol $\mathrm{HCl}$ control release tablet and it provided a drug release profile comparable with Zydol SR [74].

\section{Microcrystalline and spray dried lactose}

Dey et al. (2010) produced co-processed excipient of various ratio combination of microcrystalline cellulose, spray dried lactose and pearlitol. The study concluded that co-processed excipient of microcrystalline and spray dried lactose at 90:10\% w/w was the optimum formulation which showed good compressibility and fast disintegration. The product was applied to formulate paracetamol orally disintegrating tablet [75].

\section{Sodium carbonate and polyethylene glycol}

The invention is a pH modifier developed by Davar et al. (2010) using a fluid bed spray granulation method. Polyethylene glycol protects sodium carbonate from moisture which results in caking. The said invention was applied in the non-effervescent pharmaceutical composition of zolpidem and scopolamine [76].

\section{Starch and magnesium silicate}

Adnan et al. (2011) co-processed starch with magnesium silicate. Starch was suspended in a suspension first followed by addition of magnesium silicate. The suspension was then filtered, washed and dried. The dried product was used to prepare tablets with high mechanical strength, short disintegration time and low lubricant sensitivity [77].

\section{Lactose, MCC and cornstarch}

Akram et al. (2011) developed co-processed micro-granules of lactose monohydrate, MCC and cornstarch by wet granulation. The finished product was claimed to have the strong binding ability, fast disintegration time and improved flow property [78].

\section{$\alpha$-chitin and mannitol}

Al Omari et al. (2011) published research on the development of $\alpha$ chitin and mannitol co-processed excipient by fluid bed spray granulation method. The invention was applied in the orally 
disintegrating tablet to contribute to exclusive hardness, low friability, low ejection force while retaining rapid disintegration properties [79].

\section{Dibasic calcium phosphate, HPMC and crospovidone}

Deorkar et al. (2011) formulated an invention by co-processing dibasic calcium phosphate as a brittle material component, HPMC as binder and crospovidone as a disintegrant. The invention showed an increased flowability, API loading, and blendability and higher compatibility [80].

\section{MCC and HPMC}

Deorkar et al. (2011) prepared a co-processed excipient by spray dry granulating an aqueous slurry comprised of the microcrystalline cellulose and HPMC. Then invention has enhanced flowability, high compatibility, and increased API loading and blendability as compared to the individual components [80].

\section{Maize starch and acacia}

Olowosulu et al. (2011) developed co-processed excipient of maize and acacia by co-drying or a well dispersed aqueous mixture of the two. The drying was performed on a water bath system at $50^{\circ} \mathrm{C}$ and $80^{\circ} \mathrm{C}$ for $15 \mathrm{~min}$ with constant stirring respectively to compare the effect of partial and fully gelatinization. The fully gelatinized form showed good flowability but poor crushing strength. In contrast, the tablets produced by partially gelatinized form showed good crushing strength and friability profile [81].

\section{Calcium phosphate and MCC}

Thoorens et al. (2011) invented a calcium phosphate and MCC coprocessed excipient by mixing the aqueous slurries of microcrystalline cellulose and calcium phosphate, followed by drying such slurries to produce particulate products. The end product exhibited improved compatibility, as compared to dry physical blends of the same components [82].

\section{Polyox WSR-301 and HPMC K4M}

The co-processed excipient was reported by Gangurde and Amin (2013) using roller compaction method. Polyox WSR-301 and HPMC K4M powder samples were forced between two counter-rotating rolls and screened through 60 mesh sieve. The obtained fine powder was further recycled to get granules of uniform size. The finished product was applied to produce metformin $\mathrm{HCl}$ sustained release tablet [83].

\section{Dicalcium phosphate and carboxymethylcellulose sodium}

Ambore et al. (2014) studied on various ratio combination of dicalcium phosphate and carboxymethylcellulose co-processed using co-precipitation method. The study concluded that the flow property of the co-processed excipient improves significantly compared to the physical mixture. The excipient had good dilution potential and was used to produce a tablet with poorly compressible drugs such as paracetamol and ibuprofen [29].

\section{Dicalcium phosphate and carboxymethylcellulose sodium}

The invention was developed by Ambore et al. (2014) using coprecipitation technique. Carboxymethylcellulose was dispersed in water to allow it to swell. Dicalcium phosphate was dispersed in another portion of water. The two portions of dispersion were mixed and dried in tray dried. The invention was reported to have better flowability and dilution potential [29].

\section{Chitosan and Eudragit S-100}

Pawar et al. (2014) prepared a co-processed excipient of chitosan and Eudragit S-100 using the solvent evaporation method. The coprocessed excipient was applied to produce venlafaxine $\mathrm{HCl}$ sustained release tablet via direct compression [84].

\section{Lentinus tuber regium base co-processed excipient}

Ugoeze and Nkoro (2015) developed a co-processed excipient by mixing Lentinus tuber regium, sodium bicarbonate, tartaric acid and citric acid using solvent evaporation method. The end product appears as a compactable, tasteless, off-white powder without distinct odor. The flow property, compressibility, and dilution potential were improved [12].

\section{Marketed products}

There are many marketed products of co-processed excipients available. The marketed products are presented in table 1.

Table 1: Products of co-processed excipients which are available in the market

\begin{tabular}{|c|c|c|c|c|}
\hline Trade name & Excipients & Manufacturer & Added advantage & Reference \\
\hline Ludipress & Lactose, kallidon 30, kallidon CL & BASF & $\begin{array}{l}\text { Low degree of } \\
\text { hydroscopicity, good } \\
\text { flowability, tablet hardness } \\
\text { independent of machine } \\
\text { speed }\end{array}$ & 85 \\
\hline Cellactose & Lactose and cellulose & Meggle & $\begin{array}{l}\text { High compressibility, good } \\
\text { mouth feel, better tableting } \\
\text { at low cost }\end{array}$ & 86 \\
\hline Dipac & Sucrose and dextrin & Penwest Pharm & Directly compressible grade & 87 \\
\hline Prosolv & $\begin{array}{l}\text { Microcrystalline cellulose and silicon } \\
\text { dioxide }\end{array}$ & Penwest Pharmaceuticals & $\begin{array}{l}\text { Better flow, reduced } \\
\text { sensitivity to wet } \\
\text { granulation, better hardness } \\
\text { of tablet, reduced friability }\end{array}$ & 88 \\
\hline Avicel ce-15 & $\begin{array}{l}\text { Microcrystalline cellulose and guar } \\
\text { gum }\end{array}$ & FMC Corp. & $\begin{array}{l}\text { Less grittiness and minimal } \\
\text { chalkiness }\end{array}$ & 89 \\
\hline Formaxx & Calcium carbonate and sorbitol & Merck & $\begin{array}{l}\text { High compressibility, } \\
\text { excellent taste masking, free } \\
\text { flow, superior content } \\
\text { uniformity, controlled } \\
\text { particle size distribution }\end{array}$ & 90 \\
\hline Microcelac & Microcrystalline cellulose and lactose & Meggle & $\begin{array}{l}\text { Capable of formulating high } \\
\text { dose, small tablets with } \\
\text { poorly flowable active } \\
\text { ingredients }\end{array}$ & 91 \\
\hline Starlac & Lactose and maize starch & Meggle & $\begin{array}{l}\text { Good flowability due to } \\
\text { spray drying, the acceptable } \\
\text { crushing force due to lactose } \\
\text { content and rapid } \\
\text { disintegration depending on }\end{array}$ & 56 \\
\hline
\end{tabular}




\begin{tabular}{|c|c|c|}
\hline Pharmatose DCL 40 & $\beta$-lactose and anhydrous lactitol & DFE Pharm \\
\hline Starch 1500 & Amylose, amylopectin, and starch & Colorcon \\
\hline Pearlitol SD & Granulated mannitol & Roquette \\
\hline Advantose FS-95 & Fructose and starch & SPI Poly \\
\hline
\end{tabular}

Finlac DC

Plasdone S-630

Lycatab C

Copovidone

Ludiflash

Orocell 200 and Orocell 400

\section{Cel-O-Cal \\ Tablettose \\ Xylitab \\ StarCap 1500}

Vitacel VE-650

LustreClear

Pharmaburst

Effersoda

Sorbcel M
Vinyl acetate and vinyl pyrolidone

ISP

Pregelatinized starch

Kollidon VA 64 and plasdone S630

Roquette

Mannitol, crospovidone and polyvinyl acetate

Spheronized mannitol

Microcrystalline cellulose and calcium sulphate

Spray dried lactose (agglomerated form)

Xylitol and sodium

carboxymethylcellulose

Maize starch and pregel starch

Microcrystalline cellulose and calcium carbonate

Microcrystalline cellulose and carrageenan

Carbohydrate system, made from compendia ingredients

Sodium bicarbonate and sodium carbonate

Mannitol, polyethylene glycol, polyvinylpyrrolidone, citric acid and sodium bicarbonate

Sorbitol, mannitol,

Blanver

polyvinylpyrrolidone, citric acid and sodium bicarbonate starch.

Spherical shape particle with 92

good flowability, good

binding property and not

hygroscopic

It is a directly compressible, 93

free-flowing, USP grade of

partially hydrolyzed

cornstarch. The tablets

produced disintegrates very

fast

Suitable for chewable tablet

application with good

mouthfeel and palatability

Good mouthfeel and fast

disintegration property.

Suitable for nutraceuticals

and chewable vitamin

applications

Direct compression grade.

Good mouthfeel and fast

disintegration property.

Suitable for nutraceuticals

and chewable vitamin

applications

Good roller compaction

binder, improved hardness

and better drug dissolution

profile

Suitable for moisture

sensitive API.

Excellent flow properties

and dry binder

Suitable for high-speed

tableting, low friability, and

good flowability

Filler-binder with high

dilution potential and good

disintegrating property

Directly compressible binder

Good flowability and direct compressible

Directly compressible and $\quad 97$

good palatability

Tablet disintegration and 98

dissolution independent of

$\mathrm{pH}$

Suitable for direct

compression and

encapsulation

Efficient Tablet coating with

short hydration time prior to coating and the first drying

time

High compatibility, high

loading in, small tablets,

smooth mouth, feel, rapid,

disintegration

Improve the stability of the 2

Effervescent product

Effervescent excipients

Homogeneous and stable

mix of excipients that

dissolves completely and

rapidly, resulting in a

clear solution free of

insoluble residues

Effervescent excipients,

A homogeneous and stable

mix of excipients

that dissolves completely

and rapidly, resulting in a

clear solution free of 


\begin{tabular}{|c|c|c|c|c|}
\hline & & & insoluble residues & \\
\hline Fujicalin & DCP anhydrous & Fuji Chemicals & $\begin{array}{l}\text { Directly compressible, } \\
\text { exceptional high flow and } \\
\text { rapid } \\
\text { disintegration }\end{array}$ & 100 \\
\hline Neusilin & $\begin{array}{l}\text { Amorphous magnesium } \\
\text { aluminometasilicate }\end{array}$ & Fuji Chemicals & $\begin{array}{l}\text { Improve flow, anti-caking, } \\
\text { improve Compressibility and } \\
\text { to make solid dispersion }\end{array}$ & 101 \\
\hline F-Melt & Carbohydrate, disintegrant and DCP & Fuji Chemicals & $\begin{array}{l}\text { Directly Compressible, oral } \\
\text { Disintegrating time less than } \\
30 \text { seconds, highly flowable } \\
\text { with minimum or no } \\
\text { sticking/capping }\end{array}$ & 51 \\
\hline Sepitrap 80 & Polysorbate 80 & Seppic & $\begin{array}{l}\text { Improves the bioavailability } \\
\text { of APIs with low solubility. It } \\
\text { can be used in direct } \\
\text { compression processes }\end{array}$ & 95 \\
\hline Sepitrap 4000 & $\begin{array}{l}\text { Ethoxylated } \\
\text { hydrogenated castor } \\
\text { oil }\end{array}$ & Seppic & $\begin{array}{l}\text { Improves the bioavailability } \\
\text { of APIs with low solubility. It } \\
\text { can be used in direct } \\
\text { compression processes }\end{array}$ & 95 \\
\hline Tap-400 & Processed tartaric acid pellet & Pharmatrans & $\begin{array}{l}\text { As an acidic core for drug } \\
\text { Delivery technologies }\end{array}$ & 2 \\
\hline
\end{tabular}

\section{Future trend}

Traditional inert excipients with lack of desired functionalities have drawn the attention of pharmaceutical formulator in developing new co-processed adjuvants. The recent developments in the field of excipients, advancement in high-speed manufacturing machinery and novel co-processing techniques have further added driving force for the growth of this field. An exploration of solid-state properties of excipients and its impact on functionality is further going to fuel this trend. Moreover, increase cost in developing new chemical entity and an increasing preference for the direct compaction process create a significant opportunity for the development of highfunctionality co-processed excipients. It is predicted that the development of tailor-made designed excipients complying with safety, performance, and regulatory issues is a current and future trend in excipient technology [95]. With advantages offered by the upcoming newer combination of excipients and newer methods of co-processing, co-processed excipients are for sure going to gain attraction both from academia and pharmaceutical industry [102]. Furthermore, it opens the opportunity for development and use of single multifunctional excipients rather than multiple excipients in formulation [103].

\section{CONCLUSION}

The co-processed excipients play a pivotal role in formulating stable, result oriented drug delivery system with an improved physical, chemical and mechanical properties [104]. Furthermore, co-processed excipients solve the issues of precompression parameters, compressibility, palatability, disintegration, dissolution, and sticking which conventional individual excipients might have. Co-processed excipient is a promising tool in pharmaceutical excipient development [105]. The existing coprocessed adjuvants cannot fulfill all the functionalities required for preparation of various novel formulations. Cost is another factor that incurs increased the price of the final product. So, there is enough scope of development of new co-processed excipients to meet the demand of pharmaceutical industries. It is expected that advanced research in academia and pharmaceutical industry will surely bridge this gap in the near future.

\section{ACKNOWLEDGMENT}

The authors would like to acknowledge Pioneered Scientist Innovation Fund (PSIF grant, grant no: Proj-In-FPS-007) for sponsoring the research project. We thank Faculty of Pharmaceutical Science, UCSI University for providing facilities.

\section{CONFLICT OF INTERESTS}

The authors report no declaration of interest

\section{REFERENCES}

1. Godbole AM, Somnache SN, Thakker SP, Iliger SR, Patel BV, Suryawanshi SD. Coprocessed directly compressible excipients: a review. Uni J Pharm 2013;2:57-70.

2. Atul P, Subrata K, Ganga S. A review on co-processed excipients: a novel approach in formulation development. IJRAPI 2013;3:25-41.

3. The International Pharmaceutical Excipient Council Excipient Composition Guide. Europe; 2009.

4. Chaudhari PD, Phatak AA, Desai U. A review: co-processed excipients-an alternative to novel chemical entities. Int J Pharm Chem Sci 2012;1:1480-98.

5. Chukwu A. Key points in pharmaceutical formulation and industrial pharmacy. Nsukka: Mike Social Press; 2001. p. 1-5.

6. Nachegari SK, Bansal AK. Coprocessed excipients for solid dosage forms. Pharm Tech 2004;28:52-64.

7. Okore VC, Adikwu MU. Application of polymers in pharmaceutical sciences. In: Polymers and polymer applications. Nsukka: Jolyn Publishers; 2009. p. 49-63.

8. Reimerdes D, Aufmuth KP. Tableting withcoprocessed lactosecellulose excipient. Manufac Chem 1992;63:23-4.

9. Patel SS, Patel NM. Recent trends in direct compression technology. Pharma Buzz 2007;2:24-34.

10. Pakhale BA, Shinkar DM, Saudagar RB. Co-processed excipient: an overview. World J Pharm Res 2014;4:454-69.

11. Tobyn MJ, McCarthy GP, Staniforth JN, Edge S. Physicochemicalcomparison between microcrystalline cellulose and silicified microcrystalline cellulose. Int J Pharm 1998;169:183-94.

12. Ugoeze KC, Nkoro VO. The physico-technical properties of a multicomponent Lentinus tuberregium based co-processed excipient (Fizlent). Am J Pharma Pharmacol 2015;2:13-20.

13. Michael J, Tobyn GP, McCarthy I, John N, Staniforth SE. Physicochemical comparison between microcrystalline cellulose and silicified microcrystalline cellulose. Int J Pharm 1998;169:183-94.

14. Sudhir B, Vinay J, Shailesh S. Orally disintegrating tablets: a review. Drug Invent Today 2010;2:81-8.

15. Moreton RC. Tablet excipients to the year 2001: a look into thecrystal ball. Drug Dev Ind Pharm 1996;22:11-23.

16. Rasenack N, Muller BW. Crystal habit and tableting behavior. Int J Pharm 2002;244:45-57.

17. Liew KB, Peh KK, Tan YTF. Orally disintegrating dosage forms: breakthrough solution for non-compliance. Int J Pharm Pharm Sci 2013;5:4-8.

18. Shangraw RF, Leiberman HA, Lachman L, Schwatz JB. Pharmaceutical dosage forms: tablets. New York: Marcel Dekker; 1990. p. 195-246. 
19. Shangraw RF, Demarest DA. A survey of current industrial practicesin the formulation and manufacture of tablets and capsules. Pharm Tech 1993;17:32-44.

20. Norman AA. Tablet manufactured by direct compression. Encyclopedia of pharmaceutical technology. New York: Informa Healthcare USA; 2007;6:3673.

21. Banker UV. Role of ingredients and excipients in developing pharmaceuticals. Manufact Chem 1994;65:32-4.

22. Rubinstein MH. Tablets pharmaceutics: the science of dosage of form. $1^{\text {st }}$ edition. UK: Churchill; 1998. p. 304-21.

23. York P. Crystal engineering and particle design for the powder compaction process. Drug Dev Ind Pharm 1992;18:677-721.

24. Marwaha M, Sandhu D, Marwaha RK. Coprocessing of excipients: a review on excipient development for improved tabletting performance. Int J Appl Pharm 2010;2:41-2.

25. Flores LE, Arellano RL, Esquivel JJD. Study of load capacity of Avicel PH200 and cellactose, two direct compression excipients, using an experimental design. Drug Dev Ind Pharm 2000;26:465-9.

26. Jivraj M, Martini LG, Thomson CM. An overview of the different excipients useful for the direct compression of tablets. Pharm Sci Technol Today 2000;3:58-63.

27. Sherwood BE, Becker JW. A new class of high functionality excipients: silicified microcrystalline cellulose. Pharm Tech 1988;22:78-88.

28. Smewing J. Powder flow analysis-the solution. Manufact Chem 2002;73:32-3.

29. Ambore SM, Tekale J, Gattani SG. Investigation of novel multifunctional co-processed excipient for direct compression. World Appl Sci J 2014;31:801-10.

30. Belda PM, Mielck JB. The tableting behavior of Cellactose compared with mixtures of celluloses with lactoses. Eur J Pharm Biopharma 1996;42:325-30.

31. Patel RP, Bhavsar M. Direcetly compressible materials via coprocessing. Iran J Pharm Res 2009;1:745-53.

32. Reimerdes D. The near future of tablet excipients. Manufact Chem 1993;64:14-5.

33. Armstrong NA, Palfrey LP. The effect of machine speed on the consolidation of four directly compressible tablet diluents. J Pharm Pharmacol 1989;41:149.

34. Marwaha M, Sandhu D, Marwaha RK. Coprocessing of excipients: a review on excipient development for improved tableting performance. Int J Appl Pharm 2010;2:41-7.

35. Panda B, Raot A, Kilor V. Co-processed excipients: an overview of formulation aspects, physical characteristics, and role as a pharmaceutical aid. Pharmatutor Art 1049; 2010.

36. Limwong V, Sutanthavibul N, Kulvanich P. Spherical composite particles of rice starch and microcrystalline cellulose: a new coprocessed excipient for direct compression. AAPS PharmSciTech 2004;5:40-9.

37. Gohel MC, Parikh RK, Brahmbhatt BK, Shah AR. Preparation and assessment of novel co-processed superdisintegrant consisting of crospovidone and sodium starch glycolate: a technical note. AAPS PharmSciTech 2007;8:63-9.

38. Jacob S, Shirwaikar AA, Joseph A, Srinivasan KK. Novel coprocessed excipients of mannitol and microcrystalline cellulose for preparing fast dissolving tablets of glipizide. Indian J Pharm Sci 2007;69:633-9.

39. Barakat NS, Elbagory IM, Almurshedi AS. Controlled release carbamazepine matrix granules and tablets comprising lipophilic and hydrophilic components. Drug Delivery 2009;16:57-65.

40. Kumari MS, Prasanthi CH, Sudha Bhargavi CH, Kumari MP, Ushasri S. Reassessment of novel co-processed multifunctional excipients. IRJPAS 2013;3:122-8.

41. Gohel MC, Jogani PD. A review of co-processed directly compressible excipients. J Pharm Pharm Sci 2005;8:76-93.

42. Adeyeye MC. Roller compaction and milling pharmaceutical unit processes: Part I. Am Pharm Rev 2000;3:37-42.

43. Teng Y, Qiu ZH, Wen H. Systematical approach of formulation and process development using roller compaction. Eur J Pharm Biopharm 2009;73:219-29.
44. Bauer K, Kleeli K. Product based on polysaccharides coprocessed with an insolubledisintegrant, process for its preparation and the use. EP1167433; 2002.

45. Bauer KH. Coprocessed polysaccharide product with insolublecarboxymethylcellulose. EP1070740, 2001.

46. Bauer K, Streb M. Coprocessed granules of disintegrating agents. EP1201709; 2002.

47. Hapgood KP, Tan MXL, Chow DWY. A method to predict nuclei size distributions for use in models of wet granulation. Adv Powder Technol 2009;20:293-7.

48. York FP, Rowe RC. Process control and scale-up of pharmaceutical wetgranulation processes: a review. Eur J Pharm Biopharm 2000;52:269-77.

49. Liu JP, Zhang F, McGinity JW. Properties of lipophilic matrix tablets containing phenylpropanolamine hydrochloride prepared by hot melt extrusion. Eur J Pharm Biopharm 2001;52:181-90.

50. Bone A, Izebound E. Excipients on the move. IPEC Europe news. Available from: http://www.ipec-europe.org/UPLOADS/ 2004_October.pdf. [Last accessed on 15 Aug 2015]

51. Patel RP, Patel MP, Suthar AM. Spray drying technology: an overview. Indian J Sci Technol 2009;2:44-5.

52. Meggelaars MM, Biggelaar HA, Kussendrager, KD. Tabletingexcipient. US5534555, 1996.

53. Staniforth J. Pharmaceutical superdisintegrant US20050100600; 2005.

54. Staniforth J. Pharmaceutical superdisintegrant. US6660303; 2003.

55. Rao VU, Balasubramaniam J, Haldar RK. Coprocessedexcipient compositions. US20120178822; 2012.

56. Gohel MC, Jogani PD. An investigation in direct compression characteristics of co-processed lactose-starch using an experimental design. Indian J Pharm Sci. 2003;65:31-8.

57. Cucula EJ, Luengo MG, Ortega AS. Modified calcium phosphateexcipient. US7364755; 2008.

58. Mehra DK, West KP, Wiggins DJ. Coprocessed microcrystalline cellulose and calcium carbonate composition and its preparation. EP0193984; 1986

59. Lang S. Direct tableting auxillary US5006345; 1991.

60. Menon A, Gillece T, Chakrabarti S. Co-processing method for making a free-flowing compressible powder and tablet, US 5560927 A; 1996.

61. Sherwood BE, Hunter EA, Staniforth JH. Pharmaceutical excipient having improved compressibility. US5585115; 1996.

62. Ratnaraj S, Reilly Jr. WJ. Chewable pharmaceutical tablets. US5686107; 1997.

63. Bowe KE. Recent advances in sugar-based excipients. Pharma Sci Technol Today 1998;1:166-73.

64. Augello M, Vladyka RS, Dell SM. Taste masked pharmaceutical composition. US5904937; 1999.

65. Augello M, Reier GE. Microcrystalline cellulose/alginate wet granulation excipient/binder, US5985323; 1999.

66. Ibrahim N, Saraiya M. Co-processed botanical plant composition. US6232351; 2001.

67. Buliga GS, Tuason DC, Venables AC. Texture and stabilizer compositions. US6440474; 2002.

68. Cucula EJ, Luengo MG, Lana IM. Extended-release venlafaxine besylate tablets. US20060018963; 2006.

69. Norman GT, Nuguru KS, Amin AF, Chandar S. Co-processed carbohydrate system as a quick-dissolve matrix for solid dosage forms. US7118765; 2006

70. Haldar R, Ray DB, Bee TG, Etienne S, Cheng S. Synergistic binder compositions, a method for making same, and tablets of an active and said binder having advantageous hardness and friability. US20070122472; 2007

71. Li J, Carlin B, Ruszkay T. Co-processed microcrystalline and sugar alcohol as an excipient for tablet formulations. US20080131505; 2008

72. Gandhi AS, Bagde P, Morvekar HN, Pilgaonkar PS, Rustomjee MT. Orally disintegrating tablets. US20090208576; 2009.

73. Nagendrakumar D, Raju SA, Shirsand SB, Para MS. Design of fast dissolving granisetron HCL tablets using novel coprocessed superdisintegrants. J Biosci Technol 2009;1:8-14.

74. Ayyappan J, Umapathi P, Quine D. Development and evaluation of a directly compressible co-processed multifunction 
sustained release agent for tablets. Int J Pharm Pharm Sci 2010;2:201-5.

75. Dey NS, Panda BP, Rao MEB. Effect of co-processed direct compressible vehicles on fast dissolving tablets. Int J Phytother Res 2010;2:771-83.

76. Davar N, Kavalakatt P, Pather I, Ghosh S. Polyethylene glycolcoated sodium carbonate as a pharmaceutical excipient and compositions produced from the same. US20100266682; 2010.

77. Adnan B, Iyad R, Mayyas ALR, Stephen AL, Babur ZC. A novel multifunctional pharmaceutical excipient: Modification of the permeability of starch by processing with magnesium silicate. Int J Pharm 2011;411:18-26.

78. Akram M, Naqvi SBS, Gauhar S. Development of co-processed micro granules for direct compression. IJPPS 2011;3:64-9.

79. Al Omari MM, Badwan AA, Daragmeh NH. Pharmaceutical excipient, a method for its preparation and use thereof. EP2384742; 2011.

80. Deorkar N, Farina J, Miinea L, Randive S. Directly compressible high functionality granular dibasic calcium phosphate-based co-processed excipient. US20110229527; 2011.

81. Olowosulu AK, Avosuahi O, Isah AB, Ibrahim MA. Formulation and evaluation of novel co-processed excipients of maize starch and acacia gum (StarAc) for direct compression tabletting. IJPRI 2011;2:39-45.

82. Thoorens G, Leclercq B, Ruszkay T. Microcrystalline celluloseand calcium phosphate compositions useful as pharmaceutical excipients. W02011056775; 2011.

83. Gangurde AB, Amin PD. Formulation development and evaluation of metformin hydrochloride sustained release matrix tablet by using directly compressible co-processed excipient. World J Pharm Pharm Sci 2013;2:5296-308.

84. Pawar AY, Patil SH, Jadhav KR, Baviskar SR. Formulation and evaluation of matrix tablet of venlafaxine $\mathrm{HCl}$ by using directly compressible co-processed excipient. Int J Pharm Pharm Sci 2014;6:504-11.

85. Schmidt PC, Rubensdorfer CJ. Evaluation of ludipress as a multipurpose excipient for direct compression. Part 1. Powder characteristics and tableting properties. Drug Dev Ind Pharm 1994;20:2899-925.

86. Casalderrey M, Souto C, Concheiro A, Gomea Amoza JL, Martinez Pacheco R. A comparison of cellactose with TwoAd hoc processed lactose-cellulose blends as direct compression excipients. Chem Pharm Bull 2000;48:458-63.

87. Rizzuto $\mathrm{AB}$, Chen $\mathrm{AC}$, Veiga ME. Modification of the sucrose crystals structure to enhance pharmaceutical properties of excipient and drug substance. Pharm Tech 1984;8:32-9.

88. Bolhuis GK, Veen B, Wu YS, Zuuraman K, Frijlink HW. Compaction mechanism and tablet strength of unlubricated and lubricated silicified microcrystalline cellulose. Eur J Pharm Biopharm 2005;59:133-8.

89. Rojas J, Kumar V. Comparative evaluation of silicified microcrystalline cellulose as a direct compression vehicle. Int J Pharm 2011;416;120-8.
90. Uma Rani G, Begum N. Overview of co-processed excipients used to improve tabletting performance. J Adv Drug Delivery 2014;1:1-6.

91. Michoel A, Rombaut P. Comparative evaluation of co-processed lactose and microcrystalline cellulose with their physical mixtures in the formulation of folic acid tablets. Pharm Dev Technol 2002;7:79-87.

92. Bolhuis GK, Chowhan ZT. Materials for direct compression, pharmaceutical powder compaction technology, USA: Marcel Dekker; 1996; 7:419-99.

93. Monedero Perales MC, Munoz Ruiz A, Velasco Antequera MV, Jimenez-Castellanos MR. Study of the compaction mechanisms of lactose-based direct compression excipients using indentation hardness and heckel plot. J Pharm Pharmacol 1994;46:177-81.

94. Soujanya B, Pavani PG, Murthy TEGK. Co-processing of excipients: A review on excipient development for improved tabletting performance. RJPDFT 2015;7:149-55.

95. Desai U, Chavan R, Mhatre P, Chinchole R. A review: coprocessed excipients. Int J Pharm Sci Rev Res 2012;12:93-105.

96. Bolhuis GK, Zuurman K. Tableting properties of experimental and commercially available lactose granulations for direct compression. Drug Dev Ind Pharm 1995;21:2057-71.

97. Hauschild K, Picker KM. Evaluation of a new co-processed compound based on lactose and maize starch for tablet formulation. AAPS Pharm Sci 2004;6:1-12.

98. Muzikova J, Eimerova I. A study of the compaction process and the properties of tablets made of a new co-processed starch excipient. Drug Dev Ind Pharm 2011;37:576-82.

99. Brniak W, Jachowicz R, Krupa A, Skorka T, Niwinski K. Evaluation of co-processed excipients used for direct compression of orally disintegrating tablets (ODT) using novel disintegration apparatus. Pharm Dev Technol 2013;18:464-74.

100. Schlack H, Bauer Brandl A, Schubert R, Becker D. Properties of fujicalin ${ }^{\circledR}$, a new modified anhydrous dibasic calcium phosphate for direct compression: comparison with dicalcium phosphate dihydrate. Drug Dev Ind Pharm 2001;27:789-801.

101. Kanojia N, Kaur L, Nagpal M, Bala R. Modified excipients in novel drug delivery: the need of the day. IJTRM 2013;1:81-107.

102. Garg N, Dureja H, Kaushik D. Co-processed excipients: a patent review. Recent Pat Drug Delivery Formula 2013;7:73-83.

103. Kumare MM, Marathe RP, Kawade RM, Ghante MH, Shendarkar GR. Design of fast dissolving tablet of atenolol using novel coprocessed. Asian J Pharm Clin Res 2013;6:81-5.

104. Parfati N, Rani KC, Meilany M. The effect of coprocessed superdisintegrants ratio (crospovidone-sodium starch glycolate) to the physicochemical characteristics of atenolol orally disintegrating tablets. Asian J Pharm Clin Res 2018;11:318-24.

105. Parfati N, Rani KC, Charles N, Geovany V. Preparation and evaluation of atenolol- $\beta$-cyclodextrin orally disintegrating tablets using co-process crospovidone-sodium starch glycolate. Int J Appl Pharm 2018;10:190-4. 